\title{
A Meta-Analysis of Correlations between Chronic Obstructive Pulmonary Disease, Smoking, and Severity of COVID-19
}

\author{
Gigih Cita Pambudi'), Setyo Sri Rahardjo²), Sumardiyono²) \\ 1)Masters Program in Public Health, Universitas Sebelas Maret \\ 2)Faculty of Medicine, Universitas Sebelas Maret
}

Background: Corona Virus Disease 2019 (COVID-19) is a respiratory disease that can progress to severe hypoxemia with cases reaching more than 235 million cases worldwide until November 2021. The association with Chronic Obstructive Pulmonary Disease (COPD) and smoking habits are both very common globally and may increase the severity of COVID-19. However, it has not been elucidated. Given the gaps in evidence and the increasing prevalence of COVID-19, this study aimed to examine the influence of COPD and smoking habits on the severity of COVID-19 patients. Subjects and Method: This meta-analysis study was conducted with PICO as follows: Population is COVID-19 Patients. Interventions are Chronic Obstructive Pulmonary Disease and smoking habits. Comparison in the form of not having COPD and not smoking. Outcome in the form of severity of COVID-19 patients. Meta-analysis study sources were accessed using: Pubmed, Science Direct, and Google Scholar. The keywords used are "COVID-19" AND "COPD", "COVID-19" OR "COPD”, "COVID-19" AND "Smoking”, "COVID-19" OR "Smoking”, "COVID-19” AND "COPD” OR "Smoking", "COPD" AND "Smoking" AND "Severity of COVID-19 Patients". The inclusion criteria in this study were full-text and cross-sectional designs, articles reporting the Odds Ratio (OR) score and in English. The articles that have been collected were selected using the PRISMA flow diagram. The qualitative synthesis of data was tested using the Review Manager application (RevMan 5.3).

Results: The results of a meta-analysis in 11 cross-sectional studies showed that COVID-19 patients with COPD had a 3.77 times higher risk of experiencing COVID-19 severity compared to those without $\mathrm{COPD}(\mathrm{aOR}=3.77 ; 95 \% \mathrm{CI}=2.49$ to $5.69 ; \mathrm{p}<0.001)$ and covid patients with smoking habits have a risk of experiencing the severity of COVID-19 by 2.70 times higher compared to patients without smoking habits ( $\mathrm{aOR}=2.70$; CI $95 \%=1.99$ to $3.66 ; \mathrm{p}<0.001)$.

Conclusion: COPD and smoking habits increase the risk of severity in COVID-19 patients.

Keywords: COVID-19, COPD, Smoking habits.

Correspondence:

Gigih Cita Pambudi. Masters Program in Public Health, Universitas Sebelas Maret, Jl. Ir. Sutami 36A, Surakarta 57126, Central Java, Indonesia. Email: gigihcitap@gmail.com. Mobile: o82126655884 .

Cite this as:

Pambudi GC, Rahardjo SS, Sumardiyono (2021). A Meta-Analysis of Correlations between Chronic Obstructive Pulmonary Disease, Smoking, and Severity of COVID-19. J Epidemiol Public Health. 06(04): 415-425. https://doi.org/10.26911/jepublichealth.2021.06.04.03.

Journal of Epidemiology and Public Health is licensed under a Creative Commons Attribution-NonCommercial-ShareAlike 4.0 International License.

\section{BACKGROUND}

Coronavirus disease 2019 (COVID-19) is a respiratory and systemic disease that can progress to severe hypoxemia requiring some form of ventilator support in $15-20 \%$ of suspected and confirmed cases (Qiu et al., 2020). Until November 2021, there have been more than 253 million confirmed cases of Covid-19 worldwide. A total of more than 5 million confirmed cases of 
death. Most cases were found in the Americas, with a total of 95,222,009 cases (WHO, 2021). In the same case, it was also reported that clinical characteristics and outcomes of COVID-19 patients in China had a higher prevalence of COPD in patients with severe conditions and outcomes (Zhao et al., 2020) and there was a high prevalence of active smokers in severe cases of Covid-19 (Guan et al., 2020).

Risk factors related to COVID-19 are age, gender and the presence of comorbiddities. The most common comorbidities are hypertension, diabetes mellitus and heart disease (Espinosa et al., 2020). The presence of comorbidities in COVID-19 leads to a higher risk for ICU (Intensive Care Unit), mechanical intubation and death. People with COVID-19 can trigger stress conditions and increase the secretion of hyperglycemic hormones, such as glucocorticoids and catecholamines which result in an increase in blood glucose (Rehman et al., 2020). Self-reported demographics (age, gender, ethnicity, education level, staying up late deprivation index (IMD) scores and ratings), smoking, family and medical history, height, weight and blood pressure were collected by a study practitioner at the LHC (Ruparel et al., 2019). Regarding the severity of COVID-19, the current data showed the higher risk of severe infection in patients with COPD. A meta-analysis including 6 studies with 1,592 patients from Asia found an Odds Ratio (OR) for severe COVID-19 of 5.69 in COPD patients (Deslée et al., 2020).

Chronic Obstructive Pulmonary Disease (COPD) is a chronic inflammatory lung disease that causes obstructed airflow from the lungs that is not fully reversible, progressive and associated with an inflammatory response of the lungs to toxic or noxious particles or gases (GOLD, 2019). Symptoms of COPD include difficulty in breathing, coughing, production of mucus (sputum) and wheezing. This is caused by long-term exposure to irritating gases or particles more often, namely cigarette smoke (Chatreewatanakul et al., 2021). In a meta-analysis, two studies reported an association between mortality and congenital chronic obstructive pulmonary disease (COPD). In 2020, COPD became the fourth most common cause of death in the world with an average incidence of 4.7 million cases. Death was reported in 6 out of 10 (60\%) patients with COPD and 80 out of 223 (34\%) non-COPD patients. OR=1.93 (95\% CI= 0.59 to 7.43 ) (Zhao et al., 2020). The incidence of COPD is reported that $45 \%$ smokers are more at risk of developing COPD compared to nonsmokers (WHO, 2021). Chronic obstructive pulmonary disease (COPD) is caused by a deficiency of alpha-1 antitrypsin originating in cigarette exposure. The average number of cigarettes spent during a week reaches 76 cigarettes in urban areas and 80 cigarettes in rural areas (BPS, 2016). This shows the high number of smokers in Indonesia which is the main risk factor for COPD (Ministry of Health of RI, 2018) and causes severity in COVID-19 patients.

The pandemic has placed patients with COPD and other participant illnesses at high risk for adverse outcomes as noted in the Centers for Disease Control and Prevention (CDC) (2019). An article in the European Respiratory Journal that evaluated 1590 hospitalized cases in China confirmed that despite the low incidence of COPD (24 cases), COPD had a significant impact on risk with poor outcome (ICU admission, invasive ventilation or death) (Guan et al., 2020). The prevalence of COPD is higher in men than women with a higher tendency in men than women and tends to be higher in people with low education and middle to lower economic levels 
(Janson et al., 2013). COPD will have a negative impact on the patient's quality of life, such as increasing morbidity by producing cardiovascular disease, bronchial cancer, lung infections, thromboembolic disorders, the presence of asthma, hypertension, osteoporosis (Agustí, 2005).

This study was a systematic review and meta-analysis. This study used secondary study which the data were taken from the results of previous studies. Meta-analysis is a way of summarizing and quantitatively synthesizing various estimates produced from various similar studies to make the most accurate estimate, COVID19 is a new disease, knowledge about COVID-19 disease is not complete and developed. Many studies show that patients with obstructive pulmonary disease experience an increase in smoking severity and mortality. Most existing studies have small sample sizes. Therefore, researchers are interested in examining the effect of obstructive pulmonary comorbid smoking on COVID-19 patients using a meta-analysis. Burnout is a syndrome caused by workrelated stress and can be characterized by emotional feelings (feeling overwhelmed by work demands); depersonalization (feelings of cynicism and disinterest in work), and decreased self-achievement (decreased level of competence and work achievement) (Busireddy et al., 2017). Burnout is one of the mental health problems caused by a high workload that causes excessive stress characterized by symptoms such as anxiety and even depression, because of the seriousness of this burnout problem, WHO classifies burnout as a disease (Clough et al., 2017).

\section{SUBJECTS AND METHOD}

\section{A.Study Design}

This study is a systematic review and metaanalysis. This study used secondary data which the data were taken from the results of previous studies. A systematic review is part of a meta-analysis which presents a balanced and impartial summary of the main points of related research that has existed, usually in the form of qualitative data. Systematic Review involves a metaanalysis process (Murti, 2018).

Meta-analysis is a statistical method for combining quantitative results from various studies to produce an overall summary of empirical knowledge about a particular topic (Cheung, 2015)

\section{B. Inclusion Criteria}

1. The article used is a full paper article with the Randomized Controlled Trial (RCT) research method c

2. Articles are according to the topic

3. Full text article with cross sectional design

4. The article reports the value of the Odds Ratio (OR)

5. Research subjects are COVID-19 patients

6. Articles published in English

C. Exclusion Criteria

1. The article is not full text

2. Covid-19 patients without a history of COPD and smoking habits

\section{Operational Definition of Variables}

The search for articles was carried out by considering the eligibility criteria determined using the PICO model. The populartion in this study were Covid-19 patients. Interventions are Chronic Obstructive Pulmonary Disease and smoking habits. Comparison is in the form of not having COPD and not smoking. Outcome is the severity of COVID-19 patients.

Chronic Obstructive Pulmonary Disease (COPD) is a group of lung diseases that block the flow of air in the lungs and cause difficulty in breathing.

Smoking habit is an activity of cigarette smoking that is carried out repeatedly over a long period of time. 
Pambudi et al./ Chronic Obstructive Pulmonary Disease, Smoking, and Severity of COVID-19

\section{E. Study Instrument}

Published articles related to the influence of COPD and smoking habits on the severity of COVID-19 patients that can be accessed in full text, obtained from various databases of appropriate electronic journals include: Google Scholar, PubMed, Science Direct. This research was conducted by searching and selecting study results in various locations in the world.

\section{F. Data Analysis}

This systematic review and meta-analysis study used secondary data obtained from previous studies and data processing is carried out by using the Review Manager (RevMan 5.3)

\section{RESULTS}

The process of searching for articles by searching through a database with journals can be seen in Figure 1. The final result of the article review process showed 11 articles that fulfilled the quantitative requirements for a meta-analysis of the influence of Chronic Obstructive Pulmonary Disease and smoking habits on the severity of COVID19.

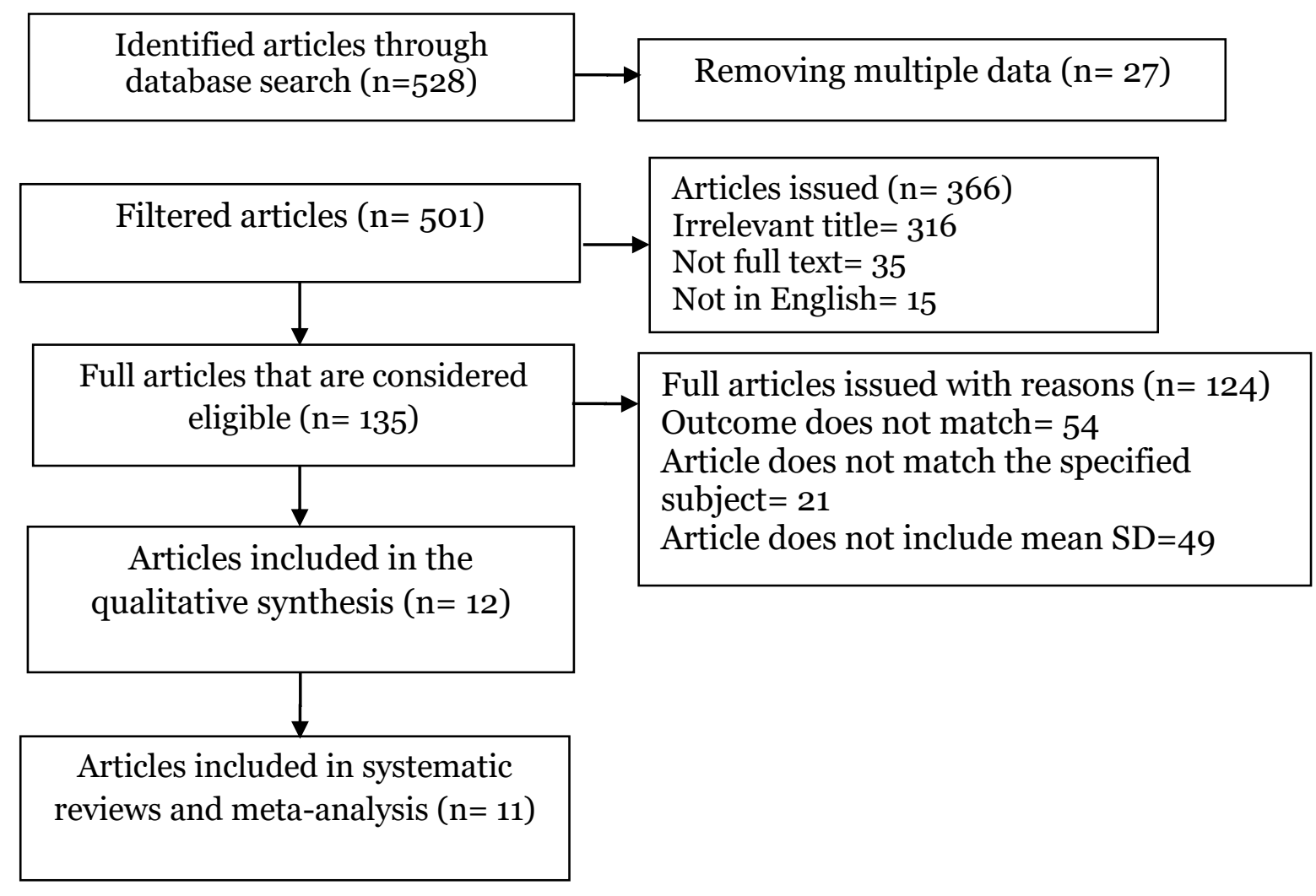

Figure 1. PRISMA Flow Diagram Study 


\section{Summary Source}

\section{a. COPD}

Table 1. Description of the primary studies included in the meta-analysis of the effect of COPD on the severity of COVID-19 patients

\begin{tabular}{|c|c|c|c|c|c|c|}
\hline Author (Year) & Country & Study Design & P (Population) & I (Intervention) & C (Comparison) & O (Outcome) \\
\hline Hu et al. (2020) & China & Cross Sectional & COVID-19 Patient & COPD & Non-COPD & Increasing the Severity of COVID-19 \\
\hline Zhao et al. (2019) & Beijing & Cross Sectional & COVID-19 Patient & COPD & Non-COPD & Increasing the Severity of COVID-19 \\
\hline Deng et al. (2019) & China & Cross Sectional & COVID-19 Patient & COPD & Non-COPD & Increasing the Severity of COVID-19 \\
\hline Lippi et al. (2020) & Italy & Cross Sectional & COVID-19 Patient & COPD & Non-COPD & Increasing the Severity of COVID-19 \\
\hline Deslee et al. (2020) & France & Cross Sectional & COVID-19 Patient & COPD & Non-COPD & Increasing the Severity of COVID-19 \\
\hline Lee et al. (2021) & South Korea & Cross Sectional & COVID-19 Patient & COPD & Non-COPD & Increasing the Severity of COVID-19 \\
\hline
\end{tabular}

\section{b. Smoking Habit}

Table 2. Description of the primary studies included in the meta-analysis of the effect of smoking on the severity of COVID19 patients

\begin{tabular}{|c|c|c|c|c|c|c|}
\hline Author (Year) & Country & Study Design & P (Population) & I(Intervention) & C(Comparison) & O (Outcome) \\
\hline Jordi et al. (2019) & Chile & Cross Sectional & COVID-19 Patient & Smoking Habit & No Smoking Habit & asing the Severity of COVID-19 \\
\hline Liu et al. (2020) & Italy & Cross Sectional & COVID-19 Patient & Smoking Habit & No Smoking Habit & Increasing the Severity of COVID-19 \\
\hline Richard et al. (2020) & South Africa & Cross Sectional & COVID-19 Patient & Smoking Habit & No Smoking Habit & Increasing the Severity of COVID-19 \\
\hline Vivek et al. (2020) & USA & Cross Sectional & COVID-19 Patient & Smoking Habit & No Smoking Habit & Increasing the Severity of COVID-19 \\
\hline Zaeo et al. (2020) & China & Cross Sectional & COVID-19 Patient & Smoking Habit & No Smoking Habit & Increasing the Severity of COVID-19 \\
\hline
\end{tabular}




\section{Study Quality Assessment}

\section{a. COPD}

Table 3. Assessment of the Quality of Study on the Effect of COPD on the Severity of COVID-19 Patients using Critical Appraisal CEBMa (Center for Evidance-Based Medicine)

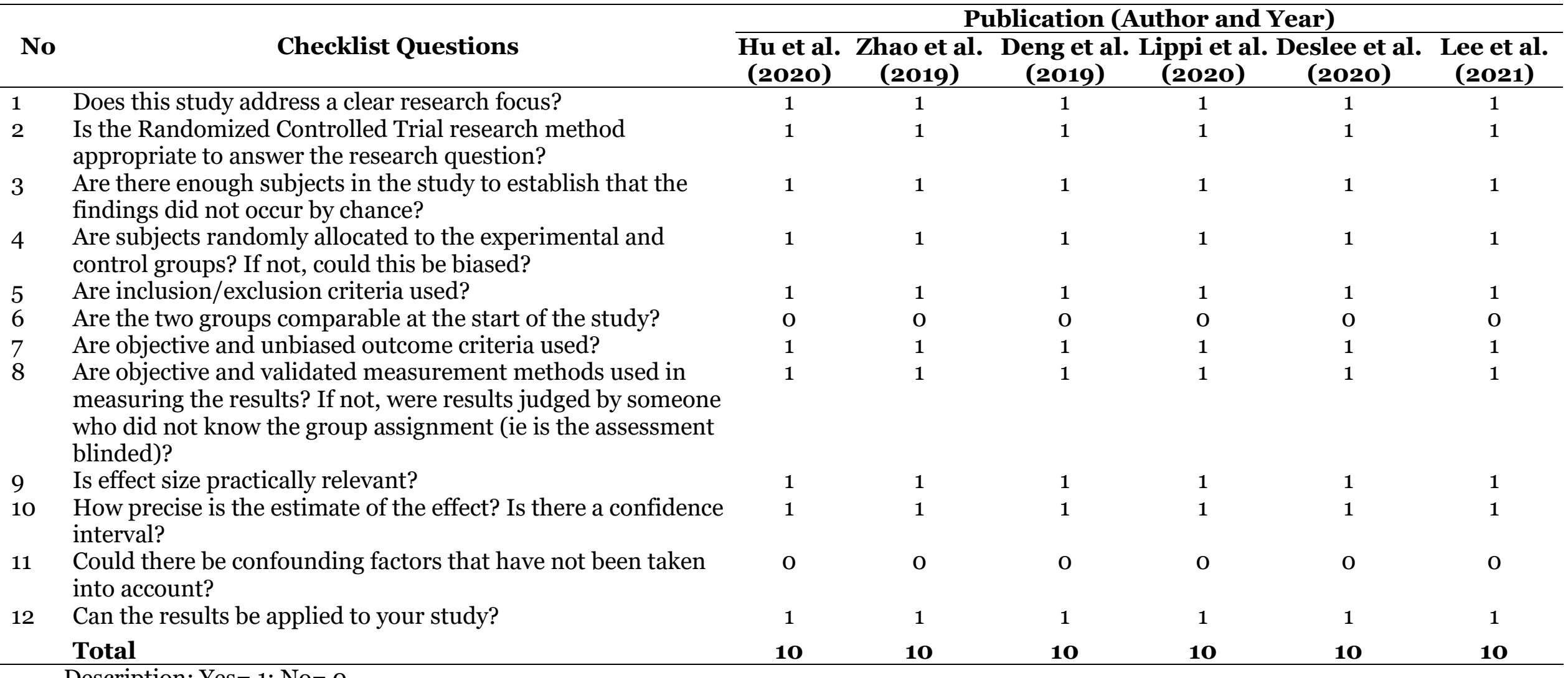

Description: $\mathrm{Yes}=1 ; \mathrm{No}=\mathrm{O}$ 


\section{b. Smoking Habit}

Table 3. Assessment of the Quality of Study on the Effect of Smoking Habits on the Severity of COVID-19 Patients using Critical Appraisal CEBMa (Center for Evidance-Based Medicine)

\begin{tabular}{|c|c|c|c|c|c|c|}
\hline \multirow[b]{2}{*}{ No } & \multirow[b]{2}{*}{ Checklist Questions } & \multicolumn{5}{|c|}{ Publication (Author and Year) } \\
\hline & & $\begin{array}{l}\text { Jordi et } \\
\text { al. (2019) }\end{array}$ & $\begin{array}{l}\text { Liu et al. } \\
\text { (2020) }\end{array}$ & $\begin{array}{l}\text { Richard et } \\
\text { al. (2020) }\end{array}$ & $\begin{array}{l}\text { Vivek et al. } \\
\text { (2020) }\end{array}$ & $\begin{array}{l}\text { Zaeo et al. } \\
\text { (2020) }\end{array}$ \\
\hline 1 & Does this study address a clear research focus? & 1 & 1 & 1 & 1 & 1 \\
\hline 2 & $\begin{array}{l}\text { Is the Randomized Controlled Trial research method appropriate to } \\
\text { answer the research question? }\end{array}$ & 1 & 1 & 1 & 1 & 1 \\
\hline 3 & $\begin{array}{l}\text { Are there enough subjects in the study to establish that the findings did } \\
\text { not occur by chance? }\end{array}$ & 1 & 1 & 1 & 1 & 1 \\
\hline 4 & $\begin{array}{l}\text { Are subjects randomly allocated to the experimental and control groups? } \\
\text { If not, could this be biased? }\end{array}$ & 1 & 1 & 1 & 1 & 1 \\
\hline 5 & Are inclusion/exclusion criteria used? & 1 & 1 & 1 & 1 & 1 \\
\hline 6 & Are the two groups comparable at the start of the study? & $\mathrm{O}$ & $\mathrm{O}$ & $\mathrm{O}$ & $\mathrm{O}$ & $\mathrm{O}$ \\
\hline 7 & Are objective and unbiased outcome criteria used? & 1 & 1 & 1 & 1 & 1 \\
\hline 8 & $\begin{array}{l}\text { Are objective and validated measurement methods used in measuring the } \\
\text { results? If not, were results judged by someone who did not know the } \\
\text { group assignment (ie is the assessment blinded)? }\end{array}$ & 1 & 1 & 1 & 1 & 1 \\
\hline 9 & Is effect size practically relevant? & 1 & 1 & 1 & 1 & 1 \\
\hline 10 & How precise is the estimate of the effect? Is there a confidence interval? & 1 & 1 & 1 & 1 & 1 \\
\hline 11 & $\begin{array}{l}\text { Could there be confounding factors that have not been taken into } \\
\text { account? }\end{array}$ & O & $\mathrm{O}$ & $\mathrm{O}$ & O & $\mathrm{O}$ \\
\hline 12 & Can the results be applied to your study? & 1 & 1 & 1 & 1 & 1 \\
\hline & Total & 10 & 10 & 10 & 10 & 10 \\
\hline
\end{tabular}

Description: $\mathrm{Yes}=1 ; \mathrm{No}=\mathrm{O}$ 
Pambudi et al./ Chronic Obstructive Pulmonary Disease, Smoking, and Severity of COVID-19

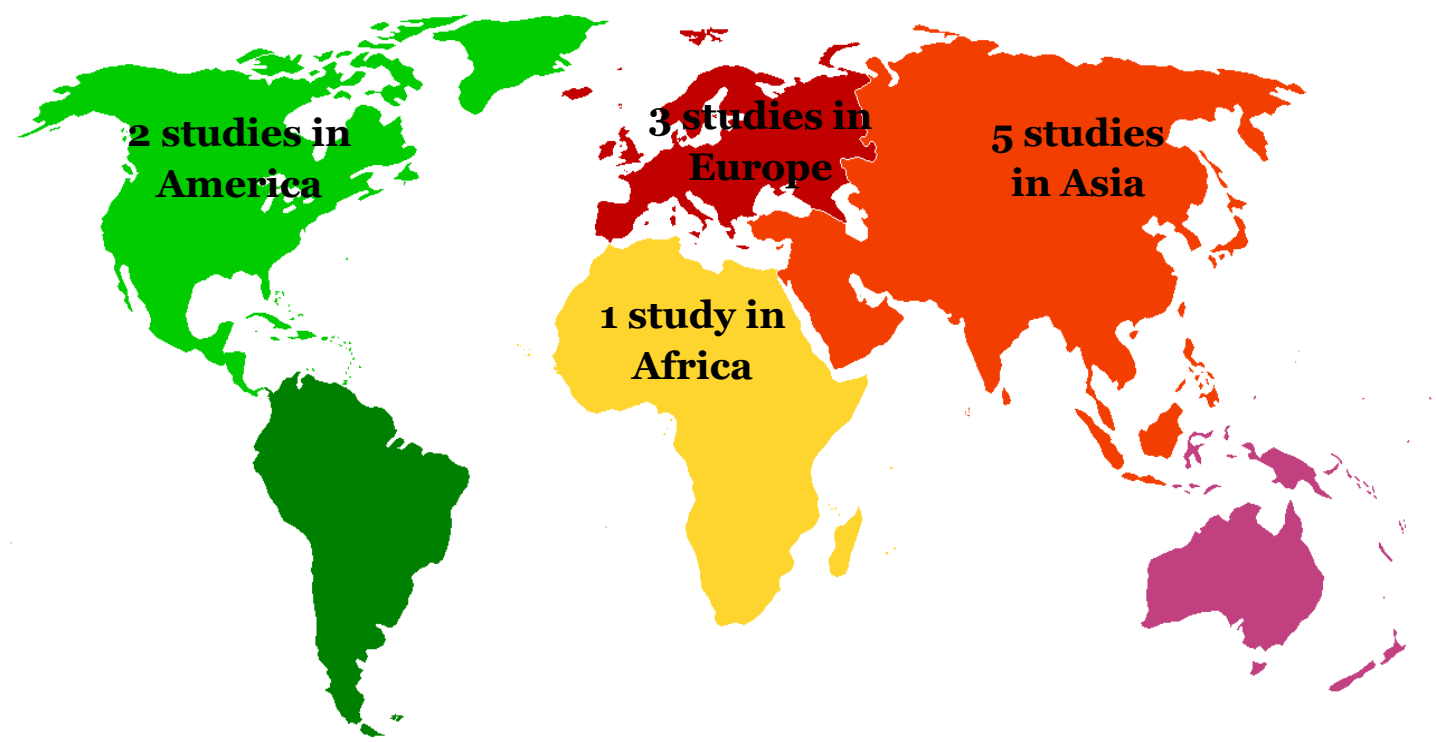

Figure 2. Map of Research Areas of the Effect of COPD and
Smoking Habits on Severity Among COVID-19 Patients

\section{Forest Plot}

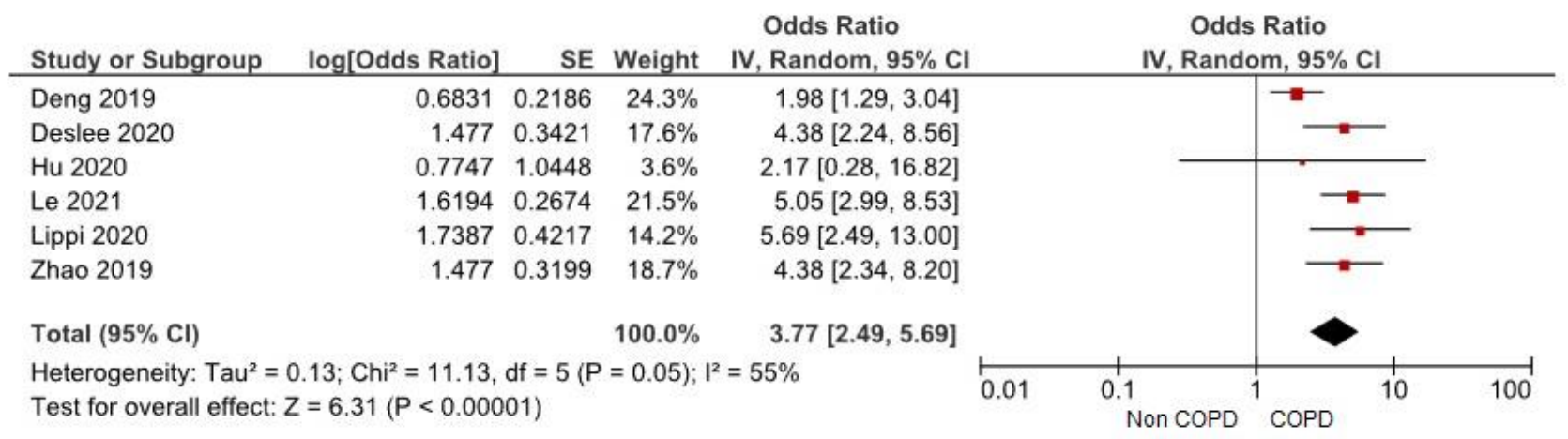

Figure 3. Forest plot of meta-analysis of the COPD effect on COVID-19 patients severity

\begin{tabular}{|c|c|c|c|c|c|c|c|c|c|}
\hline Study or Subgroup & log[Odds Ratio] & $\mathrm{SE}$ & Weight & $\begin{array}{l}\text { Odds Ratio } \\
\text { IV, Fixed, } 95 \% \mathrm{CI}\end{array}$ & & $\begin{array}{l}\text { Odds } \\
\text { IV, Fixe }\end{array}$ & $\begin{array}{l}\text { s Ratio } \\
\text { d, } 95 \% \mathrm{Cl}\end{array}$ & & \\
\hline Jordi 2019 & 1.7716 & 0.6097 & $6.4 \%$ & $5.88[1.78,19.43]$ & & & & & \\
\hline Liu 2020 & 1.7387 & 0.4217 & $13.5 \%$ & $5.69[2.49,13.00]$ & & & & & \\
\hline Richard 2020 & 0.9361 & 0.429 & $13.0 \%$ & $2.55[1.10,5.91]$ & & & & & \\
\hline Vivek 2020 & 1.0682 & 0.377 & $16.9 \%$ & $2.91[1.39,6.09]$ & & & $\longrightarrow$ & & \\
\hline Zaeo 2020 & 0.6831 & 0.2186 & $50.2 \%$ & $1.98[1.29,3.04]$ & & & - & & \\
\hline Total $(95 \% \mathrm{Cl})$ & & & $100.0 \%$ & $2.70[1.99,3.66]$ & & & & & \\
\hline \multicolumn{4}{|c|}{$\begin{array}{l}\text { Heterogeneity: } \mathrm{Chi}^{2}=6.82, \mathrm{df}=4(P=0.15) ; \mathrm{I}^{2}=41 \% \\
\text { Test for overall effect: } Z=6.42(P<0.00001)\end{array}$} & & 0.01 & $\begin{array}{l}0.1 \\
\text { Non smoking }\end{array}$ & 1 Smoking & 10 & 100 \\
\hline
\end{tabular}

Figure 4. Forest plot of meta-analysis of smoking habit effect on COVID-19 patients severity 
Pambudi et al./ Chronic Obstructive Pulmonary Disease, Smoking, and Severity of COVID-19

Based on the results of the analysis in Figure 3, it can be seen from 5 articles reporting that COPD increased severity in COVID-19 patients. Based on the analysis, there was high heterogeneity $\left(\mathrm{I}^{2}=55 \%\right.$; $\mathrm{p}$ $<0.001)$ so that the Fixed Effect Model was used (FEM).
COVID-19 patients with COPD increased the severity of COVID-19 by 3.77 times higher than those without COPD and it was statistically significant (SMD: 3.77 ; 95\% CI= 24.9 to 5.69; $\mathrm{p}<0.001)$.

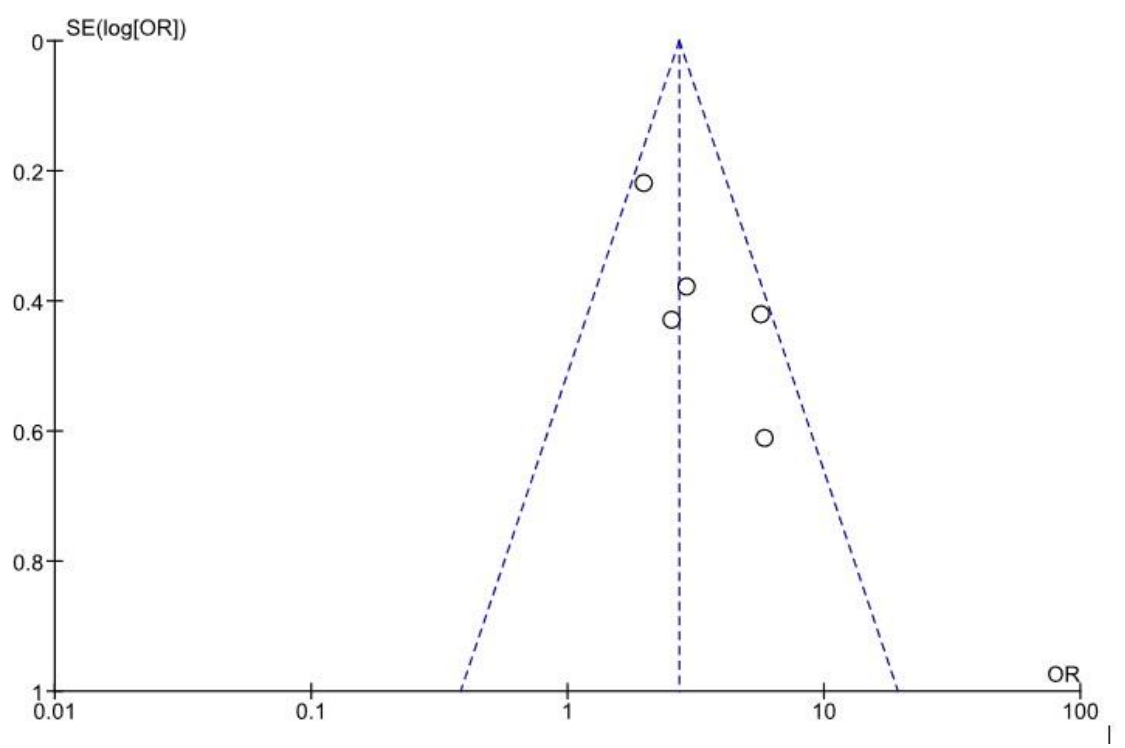

Figure 5. Funnel plot of meta-analysis of the COPD effect on COVID-19 patients severity

Based on Figure 5, it can be seen that there was a publication bias which was indicated by the asymmetry of the right and

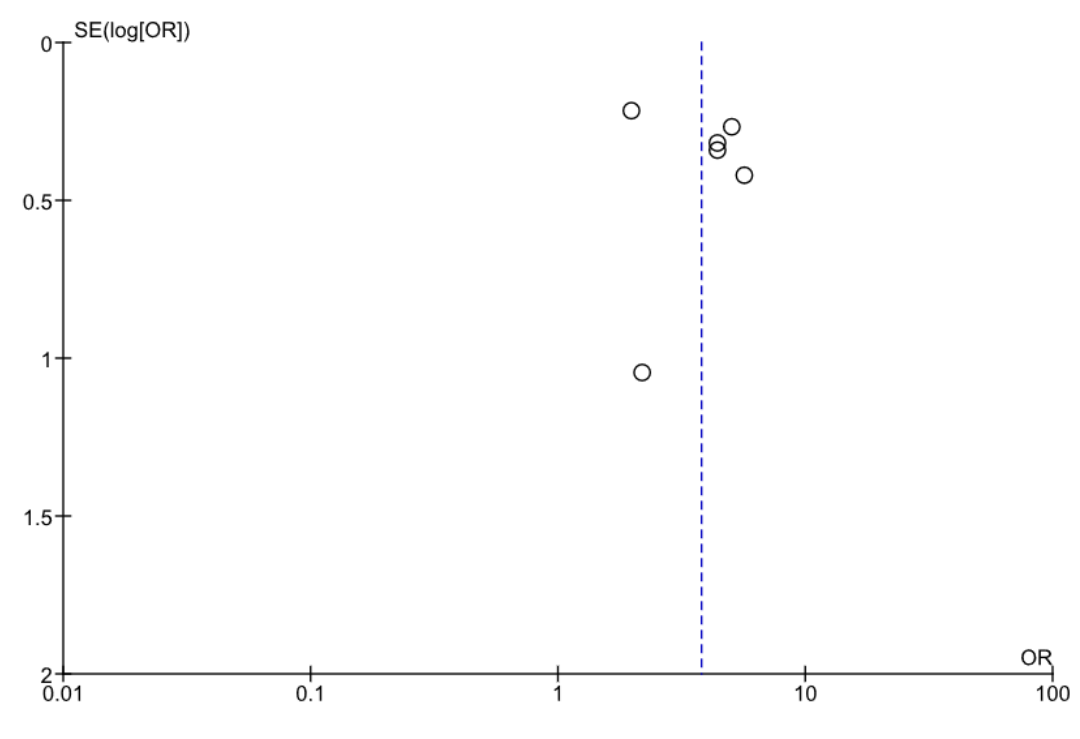

Figure 6. Funnel Plot of meta-analysis of smoking habit effect on COVID-19 patients severity 
The results of the meta-analysis can be seen in (figure 3) which showed that COVID-19 patients with smoking habits increased the severity of COVID-19 by 2.70 times compared to patients without smoking habits (SMD: 2.70 ; $95 \% \mathrm{CI}=1.99$ to 3.66 ; $\mathrm{p}<0.001$ ) heterogeneity between trials $\left(\mathrm{I}^{2}=55 \% ; \mathrm{p}<0.001\right)$ so that the Fixed Effect Model (FEM) was used.

\section{DISCUSSION}

The results of the meta-analysis showed that there was a significant effect between COPD and smoking habits on the severity of COVID-19 patients.

Lippi et al. (2020) concluded that COPD was significantly associated with the severity of COVID-19 infection, which was 5.69 times more at risk of causing the severity of COVID-19 patients compared to patients without COPD.

Zhao et al. (2020) reported that the presence of COPD had an effect on the development of the severity of the condition of COVID-19 patients by 4.38 times compared to those without COPD, while patients with smoking habits had a 1.98 times higher risk of experiencing the severity of the condition compared to patients without smoking habits.

The influence of smoking habits on the severity of COVID-19 patients tends to be controversial. Lippi et al (2020) showed that active smoking was not associated with the severity of the condition of COVID-19 patients. These results contradict the study by Zhao et al (2020) where active smoking can increase the risk of experiencing the severity COVID-19 patients condition by 2 times higher than patients who do not smoke.

\section{AUTHORS CONTRIBUTION}

Gigih Cita Pambudi as the main researcher is the executor of the study who collected the data, formulated study articles, and processed the data. Setyo Sri Rahardjo played a role in formulating the framework of thinking and analyzing the data. Sumardiyono has a role in the background and discussion of the study.

\section{FUNDING AND SPONSORSHIP}

This study used personal fund from the researchers.

\section{CONFLICT OF INTEREST}

There was no conflict of interest in this study.

\section{ACKNOWLEDGMENT}

The authors would like to thank the Ministry of Health of the Republic of Indonesia, Universitas Sebelas Maret Library, and also several Electronic databases: Pubmed, Science Direct and Google Scholar.

\section{REFERENCES}

Chatreewatanakul B, Othaganont P, Hickman RL (2021). Early symptom recognition and symptom management among exacerbation COPD patients: A qualitative study. Appl Nurs Res. 63: 151522. doi: 10.1016/j.apnr.2021.151522.

Deslée G, Zysman M, Burgel P-R, Perez T, Boyer L, Gonzalez J, Roche N (2020). Chronic obstructive pulmonary disease and the COVID-19 pandemic: Reciprocal challenges. Respir Med Res. 78: 100764. doi: 10.1016/j.resmer.2020.100764.

Espinosa OA, Zanetti ADS, Antunes EF, Longhi FG, Matos TAD, Battaglini PF (2020). Prevalence of comorbidities in patients and mortality cases affected by SARS-CoV2: A systematic review and meta-analysis. Rev Inst Med Trop Sao Paulo. 62: 1-13. doi: 10.1590/S1678-9946202062043. 
Pambudi et al./ Chronic Obstructive Pulmonary Disease, Smoking, and Severity of COVID-19

Guan WJ, Ni ZY, Hu Y, Liang WH, Ou CQ, He JX, Liu L, et al. (2020). Clinical Characteristics of Coronavirus Disease 2019 in China. N Engl J Med. 382 (18): 1708-1720. doi: 10.1056/NEJMoa2002032.

Guan WJ, Liang WH, Zhao Y, Liang HR, Chen ZS, Li YM, Liu XQ, et al. (2020). Comorbidity and its impact on 1590 patients with COVID-19 in China: a nationwide analysis. Eur Respir J. 55(5): 2000547. doi: 10.1183/13993003.00547-2020.

Lee SC, Son KJ, Han CH, Park SC, Jung JY (2021). Impact of COPD on COVID19 prognosis: A nationwide populartion-based study in South Korea. Scientific Reports. doi: 10.1038/s41598-021-83226-9.

Lippi G, Henry BM (2020). Chronic obstructive pulmonary disease is associated with severe coronavirus desease 19 (COVID-19). Respir Med. 167: 105941. doi: 10.1016/j.rmed.2020.105941.
Murti, B. (2018). Prinsip dan metode riset epidemiologi (5th ed.) (Principles and methods of epidemiological research (5th ed.)). Studi Ilmu Kesehatan Masyarakat, Program Pascasarjana, Universitas Sebelas Maret.

Zhao Q, Meng M, Kumar R, Wu Y, Huang J, Lian N, Deng Y, et al. (2020). The impact of COPD and smoking history on the severity of Covid 19: A systemic review and meta-analysis. J Med Virol. 92(10): 1915-1921. doi: 10.1002/jmv.25889.

WHO (2021). Coronavirus disease (COVID-19), Dashboard at WHO. Available at: https://covid-19.who.int/. Accessed in 2-12-21. 